\title{
Shining a light on perovskite devices
}

\author{
Could halide perovskites be of use in electronic devices beyond solar cells and LEDs?
}

n 24 April 1945, the Irish crystallographer Helen Megaw reported in Nature the crystal structure of barium titanate $\left(\mathrm{BaTiO}_{3}\right)^{1}$. The compound is a member of the family of materials known as perovskites, which have the same crystal structure and general chemical formula $\left(\mathrm{ABX}_{3}\right.$, where $\mathrm{A}$ and $\mathrm{B}$ are cations and $\mathrm{X}$ an anion) as the mineral also known as perovskite, calcium titanate $\left(\mathrm{CaTiO}_{3}\right)$. Seventy-five years later, perovskites are one of the most promising materials in optoelectronics research. But today it is metal halide perovskites, such as methylammonium lead iodide $\left(\mathrm{CH}_{3} \mathrm{NH}_{3} \mathrm{PbI}_{3}\right)$, that are the centre of attention ${ }^{2}$

Halide perovskites are solution processable. They also have high absorption coefficients and charge carrier mobilities, as well as long diffusion lengths and bandgaps that can be tuned by adjusting the concentration of halide ${ }^{3}$. As such, they are of interest in the development of solar cells ${ }^{4}$, photodetectors ${ }^{5}$ and light-emitting diodes (LEDs) ${ }^{6}$. The external quantum efficiency (EQE) of perovskite LEDs - a measure of the efficiency in which electric charge is converted to photons emitted from the device - can reach over $20 \%$ for near-infrared and some visible wavelengths ${ }^{7-9}$. In an Article in this issue of Nature Electronics, Linsong Cui, Dawei Di, Richard Friend and colleagues now show that similar efficiencies can be attained for green LEDs.

The researchers - who are based at the University of Cambridge, Zhejiang University and Hangzhou Dianzi University - achieve this using mixed-dimensional perovskites that are deposited on a polymeric hole-transport layer coated with a thin layer (around $1 \mathrm{~nm}$ ) of lithium fluoride. The thin coating allows the perovskite to be solution-processed onto hole-transport layers that are commonly used for organic LEDs and solar cells, but are otherwise too hydrophobic to grow high-quality perovskites. The approach also relies on the use of a tetraphenylphosphonium chloride additive that can control the composition of the mixed-dimensional perovskite and improve its crystallinity and luminescence. The resulting LEDs have an EQE of up to $19.1 \%$ and a brightness of more than $1,500 \mathrm{~cd} \mathrm{~m}^{-2}$.

Despite their range of valuable characteristics, the use of halide perovskites

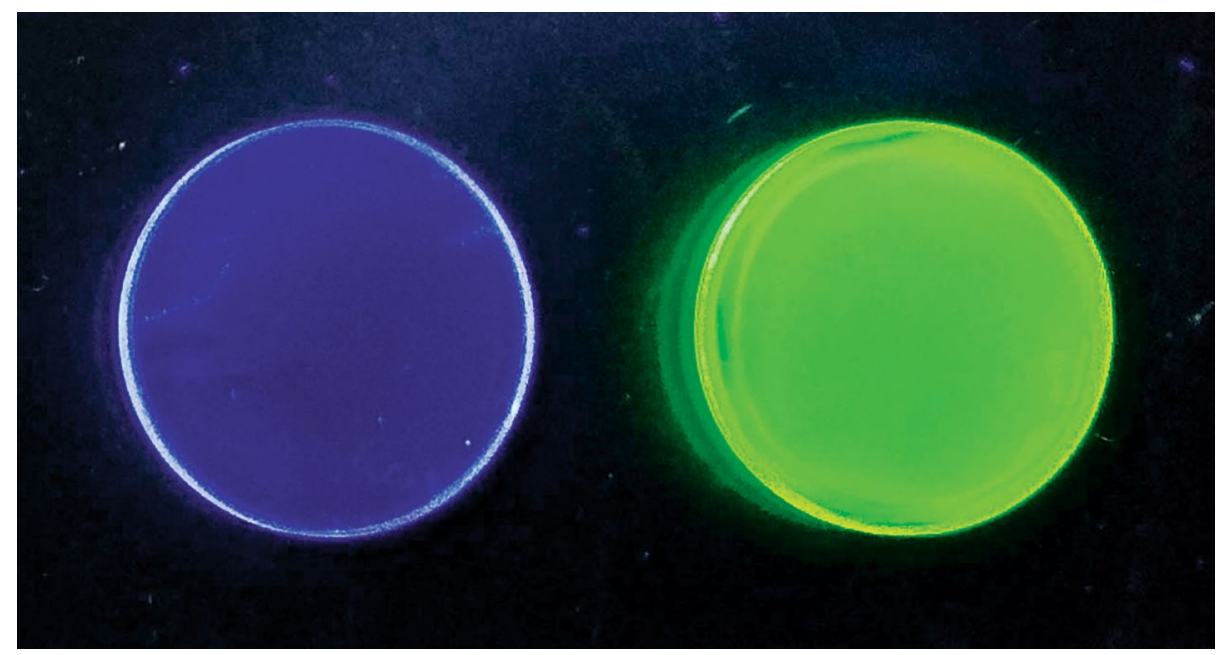

Photo taken under ultraviolet illumination of a spin-coated perovskite on a hydrophobic charge-transport layer without (left) and with (right) the insertion of a thin lithium fluoride layer. Reproduced from the Article by Cui, Di, Friend and colleagues. Credit: Springer Nature Ltd.

in electronic applications beyond optoelectronic devices remains relatively limited. Perovskite field-effect transistors (FETs) have, in particular, struggled to achieve room-temperature mobilities that match their high intrinsic mobilities due to defects at surfaces and grain boundaries, which can play a significant role in the carrier transport of transistors ${ }^{10}$. In a second Article in this issue, Henning Sirringhaus and colleagues now report a surface cleaning and passivation approach for suppressing surface ionic defects in perovskite FETs.

The technique involves three solution-based steps: a cleaning step to remove weakly bonded species from the perovskite surface, a healing step to remove surface organic halide vacancies, and a second cleaning step to remove any residual ionic species. Transistors created with the treated films have mobilities that are two to three orders of magnitude higher than those created with untreated films. The researchers - who are based at the University of Cambridge, Zhejiang University, Imperial College London, the Australian National University and the University of Oxford - create, in particular, n-type devices with mobilities of $3.0 \mathrm{~cm}^{2} \mathrm{~V}^{-1}$ $\mathrm{s}^{-1}$ and p-type devices with mobilities of 1.8 $\mathrm{cm}^{2} \mathrm{~V}^{-1} \mathrm{~s}^{-1}$ at room temperature, performance that can be increased to a maximum value of $10.6 \mathrm{~cm}^{2} \mathrm{~V}^{-1} \mathrm{~s}^{-1}$ at $80 \mathrm{~K}$.
The emergence of more advanced and more efficient perovskite optoelectronic devices looks certain to continue. For perovskite FETs, competition in the search and application of alternative semiconductors to silicon is intense and the role perovskites, which also have lingering concerns over material stability, can play here remains to be seen. But as Huihui Zhu, Ao Liu and Yong-Young Noh of Pohang University of Science and Technology note in the accompanying News \& Views to the Article by Sirringhaus and colleagues: "Research on perovskite-based transistors is still at a relatively early stage... and it will be intriguing to observe how close perovskite FETs may reach to their intrinsic performance limits."

\section{Published online: 17 November 2020} https://doi.org/10.1038/s41928-020-00509-1

References

1. Megaw, H. Nature 155, 484-485 (1945).

2. Akkerman, Q. A. \& Manna, L. ACS Energy Lett. 5, 604-610 (2020).

3. Qian, L. N. et al. Chem. Rev. 119, 7444-7477 (2019).

4. Green, M. A., Ho-Baillie, A. \& Snaith, H. J. Nat. Photon. 8, 506-514 (2014).

5. Ahmadi, M., Wu, T. \& Hu, B. Adv. Mater. 29, 1605242 (2017).

6. Liu, X.-K. et al. Nat. Mater. https://doi.org/10.1038/s41563-0200784-7 (2020).

Lin, K. et al. Nature 562, 245-248 (2018).

8. Zhao, B. et al. Nat. Photon. 12, 783-789 (2018).

9. Xu, W. et al. Nat. Photon. 13, 418-424 (2019).

10. Yu, W. et al. Nat. Commun. 9, 5354 (2018). 